\title{
Conservar o quê? Do cultivo de margens por entre as rachaduras dos muros ${ }^{1}$
}

\author{
What's to preserve? \\ The cultivation of margins in-between the cracks in the walls
}

\begin{abstract}
Adrielly Selvatici Santos; Janaína Mariano César; Luciana Vieira Caliman
Universidade Federal do Espírito Santo
\end{abstract}

\section{RESUMO:}

O presente artigo insere-se no campo de estudos da produção de subjetividade e visa problematizar a construção, em nossas sociedades atuais, de modos de subjetivação nomeados aqui como conservadoristas e/ou emparedantes. A partir da interlocução com Foucault, Guattari e Deleuze busca traçar linhas de compreensão acerca das forças de produção desses modos de subjetivação no contexto do Capitalismo Mundial Integrado (CMI) e suas políticas de massificação, bem como acerca de seus efeitos adoecedores, que se manifestam em discursos/práticas de ódio em relação às expressões estrangeiras. Traçamos a pergunta "Conservar o que?", como um exercício de escuta para invenção de saídas ao conservadorismo como força reativa, visando compreender o que é necessário conservar para que as vidas se expressem no mundo em seu caráter de variação. Com Derrida, entende-se assim a importância da conservação de um "em casa" para a vivência de um mundo compartilhado através da margem outrem.

Palavras-chave: conservadorismo; processos de subjetivação; estrangeiro; outrem; em casa.

\begin{abstract}
:
This article is part of the field of study in the production of subjectivity, and seeks to problematize the construction, in our contemporary societies, of modes of subjectivity here named as conservative and/or walled-up. From a dialogue with Foucault, Guattari and Deleuze, the article aims to trace lines of comprehension about the forces that produce these kinds of modes of subjectivity, in the context of the Integrated World Capitalism (IWC) and its politics of massification, as well as about its illness-producing effects, that are manifested in practices and discourses of hate towards expressions of foreignity. With Derrida, the article arrives in a question: "What's to preserve?", as a listening exercise to invent ways of escaping conservatism as a reactionary force. As such, it seeks to comprehend what must be preserved in order for lives to express themselves in the world, within their characteristic variation. The importance of conserving a state of "at home"ness is understood, a state made of the margins that allow us to experience a shared world through An Other, with others and with any force that expresses its otherness and strangeness to us.
\end{abstract}

Key-words: Conservatism, Processes of Subjectivation, Foreigner, An Other, At Homeness. 


\section{Fios introdutórios}

A cada tempo, a sociedade parece selecionar os estrangeiros que escolhe perseguir. Para os quais irá dizer de modos variados: você não pertence a este lugar! E sobre os quais se atribui a responsabilidade por suas desgraças e infortúnios.

No inverno de 1983, no curso do Collège de France, Michel Foucault (2010) trabalhou para colocar a importância da problemática do envolvimento do filósofo com seu presente, com seu próprio tempo. Esse problema, no entanto, não era posto apenas a filósofos. A filosofia nesse caso é tomada como exercício do pensamento, como uma atitude crítica na relação com a história, articulada menos a uma construção teórica, reduto de filósofos, e mais a uma atitude concreta de esforço pela transformação (PORTOCARRERO, 2006).

Nesse problema enfatizado por Foucault o que se indicava era uma direção para o trabalho do pensamento, para o compromisso, não do filósofo de carteirinha apenas, mas de todos nós, com uma atitude histórico-crítica, que, como elabora Rodrigues (1998) evidencia o projeto de constituição de uma “ontologia histórica de nós mesmos". O trabalho com essa experiência ontológica permite perguntar como e até onde é possível pensar de outro modo e, assim também, viver de outro modo. “(...) é a questão do presente, é a questão da atualidade, é a questão de: o que acontece hoje? O que acontece agora?" (FOUCAULT, 2010: 12).

Esta escrita articula-se a esse compromisso, a essa preocupação ontológica: a de tomar a nós mesmos como objetos de uma elaboração que é dura e complexa (FOUCAULT, 2008), e que está voltada para o presente de nossas práticas e de nossos processos de subjetivação. O que nos acontece hoje? Agora?

Em 2017, em alguns estados brasileiros, incluindo o Espírito Santo, meio à greve da Polícia Militar, por, dentre outras coisas, reivindicação da correção de sua remuneração, os jornais e redes digitais alardeiam uma verdadeira "Crise da Segurança Pública". Nesse momento, intensificam-se falas que apoiam o "armamento em nome da 'segurança'!" e o recrudescimento da força, da ordem e da lei "para combater a criminalidade!"’. Em 2018, uma cena também se conecta a esta. Há registros jornalísticos do governador eleito do Rio de Janeiro, que, em entrevista ao jornal Estado de São Paulo ${ }^{2}$, autoriza, para o fortalecimento da segurança pública, uma política do "abate". Naquela ocasião ele apontava que "o correto é matar o bandido que está de fuzil. A polícia vai fazer o correto: vai mirar na cabecinha e... fogo! Para não ter erro".

Esses discursos carreados de ódio e reatividade, sobre os quais sobram exemplos 
em nosso país na atualidade, aqui chamaremos de conservadoristas, pela lógica que atualizam. Longe de serem um amontoado de palavras ou de frases, como aponta Foucault (2012) os discursos são produzidos em redes situadas de saber-poder. Não são expressões de uma pessoa ou um grupo, mas circulam e estão presentes em diversos lugares e situações. É assim que em um dia comum em uma escola de cidade do interior, em que uma profissional, em reunião de pais e mães, conversava sobre o tema do respeito à diferença na escola, é confrontada com questionamentos como: “Aqui nessa escola, qual a posição de vocês em relação à homossexualidade? Preciso saber se matriculei meu filho em um lugar que presa pelos 'valores'!”.

Vemos então nossa atualidade sendo varrida, de modo intensivo, pelo arrefecimento de discursos machistas, racistas, homofóbicos, etnocêntricos. Presentes em declarações públicas de governantes, na conversa de bar, reuniões escolares, manifestações de rua, nas discussões de grupos de whatsapp; atravessam diferentes classes socioeconômicas e/ou níveis de escolaridade. De modo resistente também acompanhamos movimentos que insistem ante as tentativas de massificação, dominação e mesmo extermínio do outro.

Compreendemos que a insistência e a resistência, para encorajamento de um exercício de liberdade, agencia-se a esta atitude que falávamos inicialmente: histórica e crítica - sob pena de sermos tragados pelo ressentimento e impotência. Esse exercício de pensar nossas práticas e o que estamos nos tornando faz com que perguntemos sobre a produção desses discursos/práticas conservadoristas. Os discursos que parecem querer resguardar "valores" que estão sendo "perdidos", manter formas de vida ditas como "melhores" ou mais adequadas, o que querem mesmo conservar? O que se quer guardar, de modo conservador, com as posturas rígidas destrutivas, as falas excludentes e culpabilizadoras, com as práticas de extermínio e submissão do outro? O que atravessa sujeitos e grupos a ponto de parecer que a violência salva, ajuda, organiza?

Nosso exercício nessa escrita é trabalhar para ampliar o problema da conservação, que não equivale simplesmente a reter algo, ou a enrijecer. Ao mesmo tempo, visamos colocar em questão certo modo muro de construção de nossas relações uns com os outros e com o mundo, feito de conservadorismo e fechamento. Paradoxalmente, meio a discursos conservadoristas e excludentes lançamos uma pergunta: Há algo a se conservar? Há qualquer experiência, dimensão ou coisa importante a ser conservada? Inclusive a fim de fortalecer a construção de resistência aos movimentos de exclusão, autoritarismo e destruição que vivemos? O conservadorismo permitiria conservar algo efetivamente 
importante à vida? O quê na direção do fortalecimento do vivo e da liberdade é importante que se conserve?

A palavra conservar pode comparecer com diferentes sentidos. Mas, quando pensamos em políticas e práticas de existência essa palavra correntemente está associada a sentidos enrijecidos, pelos quais se busca expressar posições que visam manter a vida em um mesmo estado ou condição sem apresentar alteração, manter os "bons costumes", manter lugares, posições [privilégios, mesmo com o custo da presença de vidas existindo - e impressionantemente resistindo - em condições de miserabilidade]. Sentidos que de certo modo negligenciam uma característica fundamental da vida, do viver: a da variabilidade.

A vida não é, portanto, para o ser vivo, uma dedução monótona, um movimento retilíneo; ela ignora a rigidez geométrica, ela é debate ou explicação com um meio em que há fugas, vazios, esquivamentos e resistências inesperadas (CANGUILHEM, 2011: 140).

No presente texto, a escolha por utilizar a palavra "conservar", mesmo que perigosa, pelo fato da mesma na maior parte das vezes ressoar nos sentidos que trouxemos acima, pareceu-nos necessária. Pensamos que há algo dessa tendência de conservadorismo, em nível mundial e local, que nos diz respeito e precisa ser escutado e posto em análise. Também é importante marcar pontos de variação de sentidos quanto a esse problema, a partir dos quais acreditamos ser possível criar meios de resistência, enfrentamento e cuidado. Uma investida que busca subverter sentidos atrelados às práticas conservadoristas, porém também atenta a fazer uma análise do que se expressa nessas práticas e discursos.

Assim, à palavra 'conservar' também se associam os sentidos: fazer durar, impedir a deterioração, guardar cuidadosamente, abrigar, manter-se viva (o) [com vida ${ }^{3}$. Esses, por sua vez, não carregam em si uma dureza aversiva à variação, ao que difere, ao novo. Parecem-nos mais atrelados ao cuidado. Será que também não escutamos nesses clamores conservadoristas algo de um clamor pelo cuidado, pela não deterioração das vidas, por abrigo? Não queremos diminuir a gravidade dos efeitos de violência das ações movidas por conservadorismo e recrudescimento. Mas arriscamos perguntar se o conservadorismo, para alguns, não surge como saída, tentativa desesperada e frustrada, para dar conta de sofrimentos e encurtamento das relações? De todo modo, a saída é malograda, pois gera mais adoecimento na distância do que move a vida: a variabilidade e encontro com os estrangeiros minoritários ${ }^{4}$.

Inspiradas no pensamento de Deleuze e Guattari, a partir do qual se propõe a 
subjetividade como não substancializada em um sujeito, mas forjada no socius, por meio do entrelaçamento de linhas de forças de instâncias individuais, coletivas e institucionais, que concorrem para a produção de um si, de um modo de existir, um estilo de existência (SOARES; MIRANDA, 2008), no presente artigo tomamos o exercício de desnaturalizar os discursos/práticas conservadoristas, descolando-os da figura de determinados indivíduos ou grupos, a fim de perguntar pelas linhas que se articulam produzindo o que aqui chamaremos de modo de subjetividade conservadorista, bem como sobre seus efeitos em nosso cotidiano, para, enfim, gerarmos estratégias de resistência.

\section{O Muro Conservadorista: uma formação desejante}

O exercício de pensar a questão sobre a conservação, se há algo a se conservar, para além de todo movimento recrudescente conservadorista, leva-nos a interrogar as práticas desejantes produtoras de modos de relações opressores, excludentes e de submissão. Compreender o paradoxo colocado nas práticas e políticas conservadoristas, que buscam "conservar" determinada ordem destruindo o que parece atacá-la/ameaçá-la. Para isso tomaremos em análise o que aqui estamos a chamar de modo relacional conservadorista em seus efeitos, de modo a acompanhar fios de seu engendramento. Assim, trabalharemos um modo de compor relação com os outros sujeitos e com o mundo, marcado por práticas e discursos separatistas, privatizantes ${ }^{5}$, excludentes, emparedantes, de confinamento, que remete ao que podemos entender como sendo um modo muro de relação.

Nesse ponto é importante distinguir que ao trabalharmos com a ideia de um modo muro de relação nos remetemos a uma noção de subjetividade que diferencia-se da de sujeito ou indivíduo. Com Guattari vemos que a "(...) subjetividade não é passível de totalização ou de centralização no indivíduo" (GUATTARI; ROLNIK, 1996: 31). Não implica uma posse, um pertencimento, mas uma produção contínua que tem como superfície nossos encontros cotidianos. Contrariamente à ideia de uma "natureza humana" Guattari, e também Deleuze, situarão essa fabricação da subjetividade no registro do social. Meio a uma rede que agencia elementos muito díspares e complexos o sujeito é um produto ou um efeito transitório dessas relações de produção. Quando dizemos então de um modo relacional conservadorista ou um modo muro estamos trabalhando com a subjetivação como a produção de diferentes modos de existir, de sentir, de se relacionar consigo, com os outros e com o mundo.

Um muro, em nosso cotidiano, na sua estrutura e forma mais conhecida, são 
normalmente estruturas rígidas, altas, vedadas. Estes têm por finalidade criar uma demarcação fixa daquilo que é e daquilo que não é, do que pode entrar e do que não pode, do que sai e do que fica. Não são como as membranas plasmáticas porosas, que contornam as células do corpo humano que regulam passagens, sem impedi-las.

Quando falamos do muro como um modo, portanto, é já na pretensão de tocar a problemática que aqui está sendo tratada, a qual enuncia perguntas em relação aos muros que se obram na vida (e entre as vidas), reduzindo-a, distanciando-a da sua potência de variação, serializando e emparedando esse movimento intensivo de produção de subjetividade. Assim, pergunta-se: como entre uma vida e outra se ergue um muro? Como se forja um modo muro de se relacionar?

\section{O modo muro e sua sofisticação na passagem da sociedade disciplinar à de segurança}

Na passagem não ultrapassada da sociedade disciplinar para a de segurança (FOUCAULT, 1999), os muros, as divisões e distanciamentos tornaram-se cada vez mais sutis. Atualizaram-se como tecnologias sutis e de fácil disseminação. Nas sociedades disciplinares os aparelhos de regulação dos corpos eram visíveis, por exemplo, pela própria arquitetura dos estabelecimentos escolares e fabris. Atuava-se mais diretamente sobre os corpos, por meio de adestramento progressivo e um controle permanente. Desse modo, as marcas dessas tecnologias também podiam ser vistas no corpo dos indivíduos.

Já nas sociedades de segurança ou regulamentação, a regulação se faz por vias mais invisíveis e espalhadas. Não se procura mais estabelecer e demarcar território e sim deixar as circulações se fazerem, separar as boas das ruins, fazendo com que as coisas se mexam, desloquem-se sem cessar, de modo que possam ir perpetuamente de um ponto a outro, mas de maneira tal que os perigos inerentes a essa circulação sejam anulados. $\mathrm{O}$ processo de normalização nesse modelo se configura com o suporte matemático das probabilidades, que possibilitam a racionalização do acaso. A partir disso, é possível prever e localizar os riscos e os perigos que possam ameaçar o funcionamento de certo sistema (FOUCAULT, 1999).

Então, temos na sociedade disciplinar práticas de defesa mais voltadas à proteção do território e adestramento dos corpos, já na sociedade de segurança ou regulamentação busca-se um controle sobre a população em seus processos de vida. A população é naturalmente variável, assim necessita-se de mecanismos perspicazes para que as transformações ocorram dentro dos padrões de normalidade. Foucault (1999) nos diz que 
esses mecanismos vão se instalar no desejo, motor de ação invariante na população, por onde todos os indivíduos atuam. Ou seja, não se tem um Estado que vai atuar contra a vontade da população, e sim na vontade, na produção e modelização de subjetivação.

(...) esse desejo é tal que se deixarmos agir e contanto que o deixemos agir, em certo limite e graças a certo número de relacionamentos e conexões, acabará produzindo o interesse geral da população. O desejo é a busca de interesse para o indivíduo. $O$ indivíduo, de resto, pode perfeitamente se enganar, em seu desejo, quanto ao seu interesse pessoal, mas há uma coisa que não engana: que o jogo espontâneo ou em todo caso, espontâneo e, ao mesmo tempo, regrado do desejo permitirá de fato a produção de um interesse, de algo que é interessante para a própria população. Produção do interesse coletivo pelo jogo do desejo: é o que marca ao mesmo tempo a naturalidade da população e a artificialidade possível dos meios criados para geri-la (FOUCAULT, 1999: 95).

Entretanto, se no modelo da sociedade de segurança o que se busca é a permanência das circulações, como se passa a desejar o muro? O que se quer bloquear passagem e controlar? Que supostos perigos e riscos se quer evitar?

É importante ressaltar que Foucault afirma que o fato de haver uma transição entre os modelos de sociedade, não exclui a presença de funcionamentos da sociedade disciplinar na de segurança. Dessa passagem, queremos destacar a presença de um paradoxo. No modelo das sociedades disciplinares, as estruturas de demarcação, controle e confinamento são visíveis - escolas, fábricas, prisões, instituições asilares, de arquitetura panóptica (FOUCAULT, 2014). O erguimento dos muros fazia-se de forma literal. No contexto das sociedades de segurança ou de regulamentação, esses monumentos arquitetônicos concretos, bem como certos aparatos visíveis de controle social, foram sendo "derrubados".

Há na configuração desse modo de sociedade, uma sofisticação dos modos de controle e confinamento, pela investida no processo de massificação, a partir do qual o muro passa a operar por confinamento individualizante, o qual dá pouco espaço para os processos de invenção de si com o mundo através dos quais a diferença se instaura. Por essa mais sofisticada operação do modo muro, encontramo-nos confinados no suposto indivíduo, na suposta originalidade, no ser mais um na massa que se pensa livre nas escolhas, mas que está confinado em escolher o que está sendo apresentado.

Então, quando nos propomos analisar o modo muro queremos dar visibilidade à problemática do fechamento e distanciamento com relação à diferença, presente nas práticas e políticas conservadoristas. Visibilizar os efeitos de uma política produtora de massificação e intolerância àquilo que verdadeiramente nos aproxima: a diferença.

No contexto do Capitalismo Mundial Integrado, há muitos movimentos 
importantes que têm como direção produzir rachaduras e desmontagem de tais modos muros de ser. As políticas inclusivistas e de afirmação de direitos, diante de desigualdades sociais, etárias, etnicoraciais, de gênero e sexualidade são conquistas importantes fruto de movimentos de resistência. Muitas delas fundamentais para a promoção do acesso e ocupação de lugares que antes só eram disponíveis para os "correspondentes ao status quo padrão".

Ainda que essas mudanças vinculadas às políticas afirmativas tenham tido um caráter interventivo fundamental, na medida em que visibilizaram a produção de uma sociedade capacitista, etnocêntrica, racista, machista e patriarcal, também é preciso atentar a certo engodo produzido por determinados discursos/práticas de inclusão do "diferente" capturados pelo engendramento capitalístico, os quais muitas vezes funcionam como via de marcação do "diferente do ideal esperado" (ABREU, 2019). Essas supostas práticas inclusivas capturadas operam na produção de adaptação ao mundo regulamentado pelos "valores" conservadoristas e parecem atuarem de modo a apaziguar as diferenças do que acolhê-las.

É nesse engodo que se localiza o processo de massificação, sobre o qual discorreremos mais adiante. Quando Ricardo Reis (PESSOA, s/ano) diz no poema "Lídia" contido em suas Odes: "somos estrangeiros onde quer que estejamos" (s/pág) ${ }^{6}$, lembra-nos que diferentes todos somos e que cada um somos expressão da diferença. Essa localização dos "diferentes do ideal esperado" não é trivial e é necessário atentarmo-nos a isso para construirmos estratégias de resistência à captura.

Até aqui fizemos o caminho pensando a sociedade disciplinar e como nela os muros operavam de modo a delimitar territórios e lugares sociais pelas separações e demarcações fixas: cercavam territórios, propriedades, marcavam os estrangeiros minoritários, os marginalizados e os separavam "do social" de maneira espaço-temporal bem demarcada.

Na sociedade disciplinar a manutenção da ordem se dava por meio da docilização dos corpos, da estipulação de jornadas de trabalho, dos lugares e papéis bem estabelecidos. Na sociedade de segurança/regulamentação, por outro lado, os lugares não são bem demarcados e por um discurso de liberdade e de suposta inclusão dos estrangeiros minoritários há uma operação de captura das diferenças pela indiferenciação, em que se inclui a diferença para indiferenciar, tornar massa. Vemos, então, que o modo muro tem forte relação com processos de massificação.

Nesse sentido, no próximo ponto, discorreremos sobre o processo de 
massificação, pensando sua contribuição na constituição do modo de subjetivação conservadorista. Nele já será possível começar a localizar pistas para as questões que traçamos inicialmente no texto a respeito do problema da conservação, "conservar o que?".

\section{Os muros que se erguem como efeito do processo de massificação}

O processo de massificação faz-se a partir do desfazimento e captura das diferenças ${ }^{7}$, em que qualquer diferença que surja passa a ser circunscrita num 'universo de universais': para tudo se cria um produto, um 'modo de ser' (punk, intelectual, metaleiro). Os indivíduos 'pertencentes' a esses nichos falam, na maior parte do tempo, entre si; há pouca disponibilidade de encontro e conversa com outros nichos. Um modo de funcionamento em que todas essas diferenças capturadas por moldes identitários pudessem existir ao mesmo tempo, mas sem se tocarem. Dessa forma, tem-se certa manutenção de um funcionamento social acrítico, reprodutor e engolidor de subjetividades. Um fluxo massificante, que atropela o pensamento pelo modelo de consumo informacional.

Segundo Guattari (2010), pensar requer de nós um 'atrevimento à singularização'; requer de nós um exercício de reapropriação dos componentes da subjetividade, que se faz por uma relação de expressão e criação. Isso só é possível quando se ousa ao encontro com a diferença, irredutível aos mecanismos de controle do aparelho de Estado. Esses mecanismos de controle e de enclausuramento das sociedades de segurança agem tentando sobrecodificar todo o tempo essa dimensão de alteridade, múltipla e diferenciadora (ROLNIK, 1994), a partir de ações sutis de destituição das margens, espessura privilegiada de encontro e mistura do que é com o que pode vir a ser.

Aqui inserimos outro elemento importante nessa discussão: as margens. Os muros e as margens são de ordem completamente diferente. As margens assim como os muros contornam, porém, diferentemente destes, não se constituem de modo a impossibilitar passagens e encontro com o que está fora e com essa dimensão de alteridade. A margem demarca e inaugura o dentro e o fora, como também desfaz qualquer separação entre dentro e fora. Ela é um imbricamento dessas duas dimensões de realidade, uma zona de mistura, que se constrói pelo encontro do dentro com o fora. É condição de existência das margens que estas duas dimensões coexistam. A edificação de um muro procura preservar no sentido de manter o estado de coisa de certa ordenação de realidade de maneira atemporal, ao passo que a margem contorna uma forma no tempo, a qual se deforma e 
constitui-se em outra forma pelo incessante encontro com o que lhe é outro, seja outra forma, seja a dimensão da alteridade.

Mas, a que nos referimos quando trazemos essa dimensão que chamamos de alteridade, do invisível, do fora ${ }^{8}$ ? O fora, o exterior, a Máquina de Guerra, segundo Deleuze e Guattari (2012: 13) são:

como a multiplicidade pura e sem medida, a irrupção do efêmero e a potência da metamorfose. Fazem-valer um furor contra a medida, uma celeridade contra a gravidade, um segredo contra o público, uma potência contra a soberania, uma máquina contra um aparelho.

Ou seja, fala-se aqui acerca do plano que sempre escapa a toda tentativa de interiorização, esquadrinhamento e contenção. Aparentemente os mecanismos invisíveis de segurança tomam como perigo do qual querem se proteger tudo o que pode rachar os sistemas de controle e confinamento do Estado ${ }^{9}$, os quais se fazem em meio aberto, por uma comunicação ininterrupta de tudo a todo tempo. Sistemas de controle que se constituem em meio aberto com roupagem de liberdade. Mas, como o Estado organiza esses sistemas? Que efeitos para a população?

Tem-se, então, um aglomerado de artifícios de controle que vão se infiltrando em todos os espaços: em nossas conversas telefônicas, nas redes digitais, nos aplicativos vários dos dispositivos celulares, através das câmeras nas casas, nas ruas, etc., a fim de controlar e vigiar, conter e reapropriar-se daquilo que escapa à integralização que o capitalismo mundial produz em seus modos de governo.

Derrida (2003), ao fazer uma reflexão acerca da hospitalidade, elucidará um desarranjo no traçado da "fronteira" entre o público e o não público, falando de certa intrusão do Estado na esfera privada; como se estivéssemos submetidos a uma porosidade absoluta, uma acessibilidade sem limite dos dispositivos técnicos que rompem as fronteiras entre o público e o privado ${ }^{10}$.

O filósofo, para elucidar o que está conceituando como público e como privado, utiliza o exemplo da interceptação do Estado nas conversas de telefone, e-mail, whatsapp ${ }^{11}$. A princípio, as cartas, fax, e-mails deveriam circular livremente sem serem interceptados e as escutas e interceptações só seriam autorizadas em situações excepcionais. Mas, pergunta Derrida (2003), o que acontece quando um Estado se autoriza para além daquilo que ele deve garantir - quando, por exemplo, procura processar uma empresa que não permite o livre acesso do Estado aos conteúdos das conversas de seus usuários? O que acontece num contexto em que o Estado se reconhece no direito de controlar, vigiar, interditar trocas que os trocadores julgam privadas? 
O que Derrida conceitua por privado parecer ser mais um espaço, que, a princípio estaria resguardado do controle das autoridades, mas que, nesse modo sofisticado de controle social, é constantemente invadido. Para o autor, isso se configura em um problema com relação à hospitalidade (ao acolhimento, recebimento do outro em nossa $\operatorname{casa}^{12}$ ), uma vez que para que ela aconteça é necessário que se tenha "um espaço de casa habitável".

A problemática que Derrida nos aponta não é com relação à mistura do privado com o público, ou seja, não está propondo que uma separação total entre essas esferas seja necessária, ou que elas não se toquem. Essas trocas, afirma-nos o filósofo, compõem as constituições dos lares, uma vez que "para constituir o espaço de uma casa habitável e um lar é preciso também uma abertura, uma porta e janelas, é preciso dar passagem ao estrangeiro. Não há uma casa ou interioridade sem porta e sem janelas" (DERRIDA, 2003: 55). O que Derrida parece denunciar são as proporções e modalidades inéditas que essas circulações e conexões tomam ao ponto de que os limites entre o público e o privado sejam gravemente destituídos: produzindo massificação vulnerável a um acesso ilimitado.

Jonathan Crary (2014) parece conversar com o filósofo francês em seu livro recente que pensa as problemáticas do capitalismo tardio, elucidando uma lógica $24 / 7^{13}$ em que se é preciso ficar em constante atividade e disponibilidade, mesmo no momento do sono, ao também apontar que uma das principais formas de controle dos últimos trinta anos tem sido garantir que não haja alternativas visíveis aos padrões de vida da era da hiperconectividade, àqueles os quais resguardariam certos espaços privados, de intimidade.

Isso a que esses autores estão chamando privado não é necessariamente o individual nem o privatizado. Seriam momentos na contramão das produções de isolamento e fechamento pelo sistema. Possíveis vacúolos de não-comunicação massiva, interruptores, espaços de silêncio e de conexão com o próprio existir, mesmo no convívio com as outras pessoas e seres. Ou seja, não necessariamente trata-se de uma experiência que se deve fazer sozinho ou sozinha, de isolamento em relação ao mundo, mas no cultivo de certo estado de presença que se faz com e no mundo e momento em que estamos, a partir de exercícios de escape ao controle. A hiperconectividade, a hiperdisponibilidade, o desmanche das fronteiras e a dispersão seriam efeitos e, ao mesmo tempo, motores desses processos de individualização e isolamento, na medida em que tudo está interligado, mas não necessariamente se tocando, avizinhando, transformando.

Para Derrida (2003), esta contínua violação dos espaços de repouso, dos territórios 
em que se pode respirar, sentir-se tranquilo e protegido, tem como reação a privatização, a demarcação bruta por um muro que não deve ser ultrapassado por nada que lhe seja estranho, pois que se sente constantemente ameaçado. Uma ameaça de perda de lugar?

Por todo lado onde o "em casa" é violado, por todo lado que uma violação é sentida como tal, pode prever uma reação privatizante, seja familiarista, seja ampliando-se o círculo, etnocêntrica e nacionalista, portanto virtualmente xenófoba: não dirigida contra o estrangeiro enquanto tal, mas, paradoxalmente, contra o poderio técnico anônimo que ameaça, junto com o "em casa" as condições tradicionais de hospitalidade. A perversão, a perversibilidade dessa lei (que é também uma lei da hospitalidade) é que pode tornar virtualmente xenófobo quem protege ou pretende proteger sua própria hospitalidade, o próprio lar em que torna possível esta hospitalidade (DERRIDA, 2003:40).

Assim, temos uma produção paradoxal: uma aliança com as próprias estratégias capitalísticas e as artes de governar, controlar e vigiar, para se proteger do fora, o qual envia notícias principalmente pelos estrangeiros minoritários. A fim de manter certa estabilidade dentro das curvas normais, as forças capitalísticas de massificação e controle infiltram-se por todos os espaços, destituindo as fronteiras, deixando os indivíduos vulneráveis e enfraquecidos, pois que agem justamente sugando ao máximo suas possibilidades de resistência. Assim, regulamenta seus espaços de criação, forjando um espaço de "livre circulação" que não é livre, uma vez que é codificado e capturado pelos movimentos conservadoristas.

A livre circulação e o desmanche das fronteiras ao mesmo tempo em que parece nos aproximar por uma ilusão de que se pode estar em todos os lugares, hiperconectados, distancia-nos na mesma proporção em que ao estarmos em todos os lugares não estamos em lugar algum. Isso afeta nosso estado atencional de presença em relação ao que se passa, essencial para que a criação aconteça.

Diz-nos Deleuze (1992: 217) “criar foi sempre coisa distinta de comunicar”. O excesso de comunicação afeta as possibilidades reais de encontro, pois que todo encontro envolve a criação (de si com o outro). Criar nos demanda uma abertura ao outro, uma relação mais aproximada com o mundo em que vivemos.

Pela operação do modo muro busca-se esvaziar e controlar o encontro com o outro e com a produção da diferença, mas na sociedade de segurança isso não se faz através do erguimento de separações visíveis, mas pela instituição da indiscernibilidade provocada pelo processo de massificação. Aproximar-se do outro, da vida como experiência vertiginosa e impermanente provoca transformações, efeitos do encontro entre heterogeneidades. E como viver essas experiências de mutação fragilizados da maneira como estamos? Sem espaços de recolhimento, de respiro, pausa, de recuperação de forças, 
para que sustentemos os instantes de indeterminação que toda experiência criativa supõe?

Desse modo, criar vai nos demandar recuperar nossa vivência de um mundo compartilhado, das relações compartilhadas, que se constroem meio às margens. E aqui temos um primeiro apontamento para o que necessita ser conservado. As margens juntam e não só separam, elas são um espaço de diferenciação, criação e partilha e, em sendo assim, são necessárias para a criação de um plano de consistência. Elas não são operadas por um eu, nem por um outro, mas por outrem.

No próximo ponto, a partir de reflexões de Gilles Deleuze acerca da obra de Michel de Tournier: Sexta-feira ou os Limbos do Pacífico junto com alguns pensamentos contidos no próprio romance, tentaremos esboçar o que estamos chamando de outrem e os efeitos dessas práticas de massificação que, de algum modo, parecem destituir outrem.

\section{Reflexões sobre os efeitos de um mundo sem a margem outrem}

O romance Sexta-Feira ou os Limbos do Pacífico que, a nosso ver também é um estudo filosófico, conta a história de Robinson Crusoé, um homem que habitou sozinho uma ilha deserta durante muitos anos após o naufrágio do navio Virginie, em que toda a tripulação morreu e somente ele e o cachorro Tenn 14 sobreviveram. O romance vai contar as aventuras, as dores, as descobertas por que passou Robinson, mas também faz o leitor sentir/experimentar, junto com o náufrago, uma vida que vai acontecendo sem outrem, trazendo na narrativa a processualidade do esfacelamento da relação com outrem.

Sexta-feira foi o primeiro humano com quem o náufrago se relacionou depois de anos, um araucano que Robinson salvou sem querer quando, na verdade, pretendia matar. A vida do náufrago a partir da chegada de Sexta-feira muda, mas como afirma Deleuze (1974) em seu posfácio, não é mais uma vida com outrem e sim uma experiência outra: com outro de outrem, com a cadeia elementar, pura superfície.

Tempos depois da chegada de Sexta-feira, o navio Whitebird se ancora nas proximidades de Speranza ${ }^{14}$, mas Robinson, apesar de poder receber os tripulantes na ilha, da qual durante um período fora o governador e que, naquele momento, fazia parte de sua corporeidade, não pôde partir com aqueles homens que destinavam Speranza ao aniquilamento; que extraíam ao máximo seus recursos sem esperança de frutificação (TOURNIER, 2014) - e isso Robinson já não podia mais compreender, desde que começara a escrever o regimento da ilha.

Outro importante personagem deste romance, que emerge algum tempo depois que Crusoé já habita a ilha deserta, é o diário. Este, que comparece em vários momentos 
da narrativa, foi um importante acompanhante de Robinson "que quase chorou de alegria ao desenhar numa folha de papel as suas primeiras palavras. Parecia-lhe subitamente terse arrancado do abismo da bestialidade em que mergulhara e regressado ao mundo do espírito pelo ato sagrado: o de escrever" (TOURNIER, 2014:44). O diário era "quem" “testemunhava o curso de uma meditação sobre a vida, morte e sexo, que não era senão o reflexo superficial de uma metamorfose das profundezas de seu ser" (idem, p. 104). Este personagem aparentemente inanimado e impessoal foi ainda possibilitador de diálogo. Através dele, "um Robinson" pode (até hoje) conversar com todos os leitores possíveis ${ }^{15}$.

Esta história, então, vai tratar de uma transformação. De um Robinson que ao chegar na ilha deserta esforça-se muito para tentar sair dela a partir da construção de uma grande embarcação: Evasão; ou pela criação de uma ordem civilizatória artificial familiar: com governo, um código de leis, um código penal, com um tempo regido e organizado pela clepsidra ${ }^{16}$, à um Robinson que gradativamente vai se agenciando com Speranza; um Robinson que acolhe "um cosmos em gestação" (TOURNIER, 2014: 106), a que chama de caos.

(...) o fundo de certo cristianismo é a recusa radical da natureza das coisas, recusa essa que por demais pratiquei em relação a Speranza, e que quase foi a causa da minha perda. Só triunfarei sobre a degradação na medida em que eu saiba aceitar a minha ilha e fazer-me aceitar por ela (idem: 50).

Parece que o fato de, nos primeiros meses e talvez anos, Robinson ter se encontrado sozinho na ilha o obrigou a afastar-se da reprodução em série e automática que parecia existir no mundo 'povoado' em que vivia. Essa solidão, parece, não só o privou, mas também o permitiu experimentar certa dissolução de uma armadura de reproduções através de um encontro diferenciado com outrem: não somente com um outro eu que me percebe, como também um outro eu para mim (ROTENBERG, 2015).

A solidão tornara-o infinitamente vulnerável a tudo o que podia assemelhar-se à manifestação de um sentimento hostil, mesmo da parte do animal mais desprezível. A armadura de indiferença e ignorância recíprocas com que os homens se protegem nas relações entre eles tinha desaparecido, como um calo aos poucos amolecido em mão que se tornou ociosa (TOURNIER, 2014: 79).

Robinson, na ilha, não pudera continuar indiferente aos diversos sentimentos e existências que se passavam. Sozinho, a princípio, começa a lidar com outrem em sua dimensão impessoal: isso se dá com a experiência de escrita do diário que não é destinado a ninguém específico e sim a qualquer um. Parece, assim, que a experiência de certa solidão acompanhada (neste caso, pelo diário) foi importante para a experimentação de 
um encontro criativo com outrem; um encontro que não se reduz a relações identificatórias. O fato de outrem ter sumido aos poucos na história do náufrago não é devido unicamente à situação de estar só, mas ao fato da solidão ter se tornado uma experiência de desamparo extremo ${ }^{17}$.

Com o passar do tempo, parece que ser acompanhado unicamente pelo diário não foi suficiente. O diário, apesar de ser uma superfície de inscrição importante, que pode possibilitar acessar qualquer um, tem o limite da não reciprocidade de um afeto vivo. Quem escreve no diário diz para qualquer um, mas este qualquer um pode nunca escutar e nem mesmo reagir. O diário é um outrem que pode perigar a se tornar mesmo: meu querido diário...

Então, que é outrem? Deleuze (1974) aventura-se nesta jornada de pensamento em seu posfácio à obra de Tournier. Uma primeira marcação importante feita pelo filósofo está quando traz algumas discussões acerca desse conceito pelas teorias filosóficas. Segundo o autor, o erro dessas teorias está quando reduzem outrem a um objeto particular ou a um outro sujeito. Para ele, outrem "não é nem um objeto no campo de minha percepção, nem um sujeito que me percebe: é, em primeiro lugar, uma estrutura do campo perceptivo, sem a qual este campo no seu conjunto não funciona como faz" (p. 316). Os outros sujeitos e os outros objetos no campo seriam meios pelos quais outrem poderia (ou não) efetuar-se e isso não é um ponto qualquer.

Robinson por muitos anos esteve isolado na ilha deserta e por mais que tentasse manter certo estado de uma vida aparentemente acompanhada por outrem, não conseguiu, pois não tinha um outro semelhante ${ }^{18}$ (que pudesse possivelmente atualizar outrem) que sorrisse para ele, ou para quem pudesse sorrir. "Só o sorriso de um amigo lhe restituiria o seu (...) Mas quem, quem derreteria, pela simples virtude de um sorriso, aquele gelo que paralisava seu rosto?" (TOURNIER, 2014: 83). Ter um rosto compreende que

(...) essa parte do corpo [seja] modelada e remodelada, aquecida e permanentemente animada pela presença de nossos semelhantes. Um homem que acaba de deixar alguém com quem teve uma animada conversa: guarda-lhe o rosto por algum tempo uma vivacidade remanescente que só aos poucos se extingue e cuja a chama se reacenderá com o aparecimento de outro interlocutor (TOURNIER, 2014: 82).

Ou seja, pede que haja a possibilidade de uma conversa animada. De que se possa encontrar com um semelhante, que não é igual, nem necessariamente da mesma espécie, mas que não seja indiferente à partilha. Assim sendo, um mundo 'povoado' tal qual habitado por Robinson, antes de acontecer de Speranza tornar-se sua morada, pode igualmente atualizar essa solidão do isolamento. Na medida em que os homens se 
protejam das relações entre eles através de suas armaduras de indiferença e ignorância. Nesta conjuntura, outrem pode não se efetuar. Assim, temos como um dos efeitos da não efetuação de outrem, um homem sem rosto, ou melhor, de face congelada.

A análise que Deleuze (1974) faz da obra de Tournier também inicia desta forma, falando de uma trama que vai trazer um combate entre a terra e o ar, entre o que Deleuze aponta como plano das forças e plano das formas:

Observar-se-á que a terra e o ar desempenham menos o papel de elementos particulares do que de duas figuras completas opostas, cada qual reunindo, por conta própria, os quatro elementos. Mas a terra é o que os encerra e os estreita, contém-nos na profundidade dos corpos, enquanto o céu, com a luz e o sol, leva-os ao estado livre e puro, liberados de seus limites para formar uma energia cósmica de superfície una e, contudo, própria a cada elemento (DELEUZE, 1974: 312).

Sendo o plano das formas o das coisas "terrenas" e o plano das forças o dos elementos do céu, o filósofo vai trazer outrem como "uma estrutura" planos, que assegura as margens e transições do mundo, que regula as transformações da forma e do fundo, a qual vai possibilitar certo movimento de territorialização: Outrem "baixa os elementos na terra, a terra em corpos os corpos em objetos" (DELEUZE, 1974: 326).

A noção de território comparece na obra de Deleuze e Guattari (1996) para pensar o processo de construção de subjetividade, que diz respeito às nossas maneiras de estar no mundo como sujeitos-arranjos temporais. Segundo os autores, os territórios existenciais constituem-se por emaranhados de linhas que se encontram num movimento contínuo de tessitura. O que dá esse caráter movente é justamente o fato dos territórios engendrarem-se em relação a processos que ao mesmo tempo os constituem e que os desmancham. Ou seja, se fazem meio aos processos de desterritorialização e reterritorialização. Está-se falando aqui do movimento da vida. De vidas em movimento. E não há nada mais cruel e mortífero que estancar/barrar/calar/brecar/encurralar/emparedar essas modulações singulares, que é o que se manifesta nas práticas conservadoristas em suas tentativas de congelar a variabilidade da vida por entendê-la ou estrategicamente empregá-la: perigosa.

Um território existencial é sempre singular, o que é diferente de dizer que é fixo (não esqueçamos que a terra está sempre em movimento). Tem suas marcas. Encontros que produzem o território de uma maneira e não de outra.

É ainda pensando a produção de subjetividade, que Deleuze (1974) parece comentar a obra de Tournier (2014). Assim, ele vai trazer o que outrem opera nesta 
processualidade. Para ele, outrem operando organiza um mundo marginal, um fundo do qual outros objetos e ideias podem sair segundo leis de transição que regulam as passagens de um ao outro, não deixando que estas aconteçam de forma abrupta. É uma estrutura de tessitura de contornos permeáveis, que nos trazem um saber ou sentimento de existência marginal. Outrem ao mesmo tempo que nos lança ao possível, ao contato com àquilo que nos margeia, ampara. Faz com que este contato, as passagens e transformações decorrentes dele aconteçam de forma mais suave - ou menos abrupta.

Assim, vamos compreendendo outrem como uma margem, estrutura de contorno, contato e diferenciação, a qual na medida em que nos contorna e nos delimita em relação ao entorno, avisa-nos do fundo que está ao nosso redor, já que demarcar uma forma do fundo não necessariamente a recorta dele. As formas existem com o fundo e é como se o próprio fundo de possíveis fosse o que as contorna e também as perturba ${ }^{20}$. Desse modo, nessa confluência, cria-se a possibilidade de diferenciação/singularização, já que ao nos lançar um vago clarão sobre um universo de objetos e virtualidades situados à margem de nossa atenção, os quais podem a qualquer momento transformar-se no centro dela, outrem $^{21}$ nos desconcerta sem cessar (DELEUZE, 1974).

Na ausência de outrem, nos diz o filósofo, não há mais transições, contiguidades e semelhanças que nos permitam habitar o mundo. "Mais nada subsiste além de profundidades infranqueáveis, das distâncias e diferenças absolutas ou, então, ao contrário, de insuportáveis repetições, assim como extensões exatamente superpostas" (DELEUZE, 1974: 316). Na ausência de margens tanto temporais quanto espaciais há confusão, um deserto. Como se não houvesse mais uma coexistência e sim uma existência chapada. Em um mundo sem outrem, há o desmoronamento da categoria do possível e, com isso, ao invés de formas relativamente harmoniosas, saindo de um fundo para a ele voltar segundo uma ordem do espaço e do tempo, haverá nada mais do que linhas abstratas, luminosas e contundentes, nada mais do que um sem fundo, rebelde e sugador.

Robinson, entretanto, para Deleuze (1974), a partir do encontro com Sexta-feira e com Speranza, alcança uma grande Saúde elementar. O filósofo não categoriza a falência da estrutura outrem, fadada a um final patológico de menor potência. No contexto da ilha, com Sexta-feira, as catástrofes, o diário, a poça, etc, foi-se tramando um outro modo de experimentação na/da superfície.

Entretanto, nos interessa neste trabalho pensar a relação da "falência" ou fragilização da estrutura outrem com a operação muro e com a produção do modo de subjetividade conservadorista. No contexto do Capitalismo Mundial Integrado não 
estamos vivendo na ilha deserta, mas encontramo-nos cada vez mais na experiência de desertificação, com rostos congelados, corpos emparedados, vidas sem movimento e cronificadas por certo conservadorismo.

No posfácio, Deleuze (1974) vai trazendo algumas reações de Robinson ao desaparecimento da estrutura outrem. Primeiro há um certo desespero, a estrutura outrem ainda existe, mas não se encontra mais termos para operá-la. Depois, quando esta começa a se esboroar, há uma busca por um substituto de outrem. Este é o momento em que Robinson produz alimentos para não serem consumidos, inventa todo um regimento para o funcionamento da ilha, respaldado pelo divino. Essa segunda reação acontece de forma rígida, robotizada, com um tempo marcado pela clepsidra e por um calendário criado pelo personagem; ela era repleta de rituais e levantamento de artefatos imensos para a proteção e tentativa de recuperação de certa ordenação e "hábito que outrem dava as coisas" (idem: 323). Pensamos que a operação muro se constrói meio a este segundo momento.

Bem parecia que toda a estrutura artificial e exterior, vacilante mas contínua e febrilmente aperfeiçoada, só tinha como razão de ser proteger a formação de um homem novo que apenas mais tarde seria viável. Isso, porém, Robinson apenas em parte reconhecia e desolava-se com as imperfeições de seu sistema. De fato, a observação da Carta e do Código Penal, o cumprimento das penas infligidas a si próprio, o respeito de um emprego rigoroso do tempo que não lhe deixava o mínimo de intervalo, o cerimonial que rodeava os atos mais importantes da sua vida, todo este espartilho de convenções e prescrições que a si impunha para não cair não o impedia de sentir com angústia a presença selvagem e indomável da natureza tropical e, dentro de si, o trabalho erosivo da solidão sobre a sua alma de homem civilizado. Era inútil proibirse determinados sentimentos, determinadas conclusões instintivas: sempre caía em superstições ou perplexidades que abalavam o edifício dentro do qual se esforçava por fechar (TOURNIER, 2014: 75 -76).

Um dia, Robinson percebeu que a clepsidra havia parado. Fora a primeira vez que, depois de muito tempo, o ritmo obsessivo das gotas cessava de controlar o tempo e o menor de seus gestos com o rigor de metrônomo. Sentiu-se muito feliz. Este foi o primeiro momento em que o náufrago pensou "ter descoberto outra ilha atrás daquela onde há tanto tempo solitariamente penava, outra ilha mais fresca, mais quente, mais fraternal, que a mediocridade de suas preocupações normalmente lhe mascarava". (TOURNIER, 2014: 86). Para ele, essa descoberta foi maravilhosa, pois percebeu que "era possível escapar à implacável disciplina da rotina e das cerimônias, sem, no entanto, recair no chiqueiro! Era possível mudar sem se desvirtuar" (idem: 86). Depois disso, muitas vezes, Robinson, recorreu à parada da clepsidra. Porém, ainda não havia chegado a hora do 'novo Robinson'.

Quando Sexta-feira chega, Robinson-governador o coloca para trabalhar segundo 
esta ordem com o intuito de mantê-la. Mas, o araucano também levava uma vida à margem da ordem (TOURNIER, 2014). Com Sexta-feira, Robinson pôde viver mais esta outra ilha. Entretanto, isso não quer dizer que esta experiência somente se deu com o araucano. Como trazido anteriormente, Robinson já a havia vislumbrado antes, malgrado todas as tentativas de conservar a ordem e a disciplina, algo que já escapava. Era impossível fechar-se dentro do edifício, assim como é impossível fechar-se completamente dentro dos muros.

Há algo que não se submete. Uma força que resiste ao fechamento.

A trama de Tournier ao mesmo tempo que mostra como esta rigidez pode ser produzida, traz elementos e cenas que rompem com esta sem parar. Não há como precisar na narrativa um tempo de rigidez e outro de fluidez - havia sempre um movimento. Isso nos permite um respiro... não há muro sem rachadura para o exterior! Assim como não há uma vida sem margens. O modo de operação muro é uma produção desejante e como tal existe como uma dobra espessa, a qual, ao mesmo tempo, que se constitui em uma forma, carrega consigo as forças moventes do fora.

Existir, o que significa? Significa estar fora, sistere ex. O que está no exterior existe. $O$ que está no interior não existe. As minhas ideias, imagens, sonhos não existem. Se Speranza não é mais do que uma sensação ou um feixe de sensações, não existe. E eu próprio só existo quando me evado de mim para outrem.

No entanto, tudo se torna mais complicado, pois o que existe insiste em que se pense o contrário. Há uma grande e comum aspiração do inexistente à existência. É como uma força centrífuga que empurra para o exterior tudo o que se move dentro de mim, imagens, sonhos, projetos, fantasmas, desejos, obsessões. O que não ex-iste, in-siste. Insiste para existir. Todo este pequeno mundo se empurra à porta do grande, do verdadeiro mundo. E é um terceiro que possui a chave. Quando um sonho me agitava na cama, minha mulher sacudia-me pelos ombros para me acordar e terminar com a insistência do pesadelo. Ao passo que hoje...Mas porque voltar incessantemente a este assunto? (TOURNIER, 2014: 115-116).

Outrem exprime um mundo possível. Outrem-margem, ou nas palavras de Deleuze (1974) a priori, é a existência do possível em geral.

As práticas conservadoristas parecem sutilmente se constituir de modo a destituir outrem, e assim agem sobre o plano do possível. Essa destituição se faz por certa produção de desertificação, ainda que estando em multidão, através do processo de massificação e pela hiperconectividade, que agem de forma a reduzir a disponibilidade à partilha e ao encontro com a dimensão estrangeira da vida, disparadora de processos de singularização. Insistir no exercício do cultivo desta dimensão marginal de amparo, nesse "em casa" que não é uma interioridade, mas um mundo entrelaçado entre interior e exterior através de 
outrem, é apostar no cultivo de diferentes possíveis. É outrem que possibilita o diálogo entre formas subjetivas com o plano das forças e, com isso, que o pulsar da vida continue em sua potência de inventividade.

\section{Fios conclusivos: conservar o que?}

Desassossegadas pelas expressões dos modos de subjetividade conservadoristas que se atualizam no contemporâneo, de modo a apequenar e amesquinhar vidas (ABBES; HERCKET, 2010) buscamos desenvolver no presente artigo uma reflexão acerca das engrenagens produtoras desse modo de subjetivação, questionando o que ele denuncia como formação sintomática deste tempo com a pergunta: conservar o que?

A partir disso, analisamos as sofisticações dos modos de controle na passagem da sociedade disciplinar para a de segurança, com o processo de massificação e com certos usos dos aparatos tecnológicos de comunicação, que, com base nas reflexões de Derrida (2003) e Crary (2014), pela hiperconectividade funcionavam de forma a violar o "em casa", o que gera certa posição reativa de fechamento à dimensão estrangeira: o modo muro.

Interessadas em uma alternativa aos muros e entendendo a importância do cultivo das margens, marcadoras e instâncias de passagem na produção de diferença, como possibilidade de resistência aos processos de massificação, adentramo-nos com Deleuze e Tournier a compreender a função marginal de outrem e sua relação na construção do "em casa". Neste tópico conclusivo, discorreremos mais acerca do que precisa se conservar para que a vida possa continuar a se expressar singularmente: nosso lar, o "em casa".

O nosso lar, a nossa casa, o 'em casa', não é uma propriedade, não é o interior, não é a consciência, e nem o privado propriamente dito. Apesar de Derrida (2003) e Crary (2014) utilizarem-se desta terminologia quando vão falar acerca desses espaços de intimidade em contraposição ao que é definido como 'espaço público', é importante para este trabalho ampliar a que isso se refere, pois pode haver o perigo de se capturar em certo discurso individualista isso a que chamamos de: lugar, casa, intimidade, lar.

Referir-se a lares com janelas e portas para o estrangeiro pressupõe uma construção que se faz coletivamente. Deste modo, o nosso lar, nosso 'em casa', é uma composição que se faz através de outrem e com os outros. Ele não é necessariamente um espaço físico, mas uma experiência relacional de confiança. Assim sendo, é possível sentir-se em casa em uma praça pública, no encontro com um amigo, até mesmo num país 
estrangeiro.

O aconchego de 'nossos lares' se constitui com os elementos do fora. Um ninho, por exemplo, é construído por galhos, palhas, folhas, restos que os pássaros encontram pelos campos, florestas, cidades por onde voam. É esse material diverso achado no mundo, feito de mundo, que as aves entrelaçam fazendo seus espaços aconchegantes e quentes onde irão botar e chocar seus ovos e depois guardar seus filhotes até que eles também possam voar por aí. Ou seja, é com esses elementos de fora que se torneia um aconchegante 'dentro'. Nosso em casa, dessa forma, não se reduz a um território físico murado, mas a um território existencial margeado por outrem.

O problema com relação aos muros é que eles acabam impedindo, embarreirando também a nossa construção de casa. Nosso 'em casa' não é o eu, nem o outro, é a margem relacional de onde emerge concomitantemente 'eu' com 'outro'. O muro controla, cerceia, governa, sobrecodifica nossos co-surgimentos, barrando a nossa capacidade ou possibilidade de ver, de acompanhar e nos apropriar da coemergência - barra a criação singular que, apropriados, podemos gerar.

Um mundo sem margens, sem lar afeta os pequenos espaços onde nos criamos; nossos invólucros de confiança. E esses precisam ser conservados. A ausência destas margens nos esmaece, tornando, assim, o que chega de fora e a experiência com o fora (de estranhamento) ameaçadora. O contexto contemporâneo parece forjar um cheiro de ameaça por todos os lugares. Daí um sentimento de insegurança reafirmado e desviado por discursos e práticas estatais que o escamoteia localizando sua causa em certos indivíduos, aglomerações grupais, classes, que passam a ser consideradas perigosas.

Temos, assim, como efeito dessas práticas de destituição de margem, a construção dos muros impermeáveis, expressos nos endurecimentos das identidades nacionais, de raça, de gênero, de grupos; nas práticas xenófobas, racistas, homofóbicas, machistas; nos pedidos por ditadura militar, no ódio pelo que nos é estranho e provoca estranhamento no status quo. Não é o Estado que constrói os muros à revelia da população, os muros são levantados por uma operação desejante. As pessoas pedem pelos muros, elas operam na construção dos muros. O outro (e a alteridade) só se torna um perigo para minha existência por uma sensação constituída de que aparentemente a existência dele se faz à custa de minha própria.

Por isso nossa insistência em perguntar acerca dos processos de construção dos muros de isolamento, mesmo em nossa sociedade em que, aparentemente, estamos conectados o tempo todo. Pois mesmo que estejamos comunicados, não estamos 
partilhando. O excesso de fala, de informações, de emissão de opiniões velozes, de construção de teorias sobre as coisas só reafirma e aumenta a distância em relação a nós mesmos e ao nosso entorno. Aí mora a grande violência que se vive no contemporâneo: o silenciamento e abafamento das existências, impossibilitadas de expressar-se no mundo. Essa violência primeira tem como efeito as demais: destrutivas, bélicas, defensivas.

O que está posto na construção dos muros não é só uma defesa em relação à morte, mas, e, principalmente, uma defesa em relação a certo "espaço" constantemente destituído e ameaçado pela intrusão dos mecanismos de controle. O medo em relação à morte parece secundário ao medo de destituição do lugar e até da desintegração de si. A evitação das pequenas mortes parece se construir na medida em que nos sentimos desprotegidos e fracos para suportar os momentos de desestabilização, como se esses fossem vividos de uma maneira exagerada, posto que toda possibilidade de mudança passa a ser vivida como uma ameaça à perda de tudo.

Perguntar pelo processo de produção dessas barreiras nos ajuda a pensar em possíveis formas de resistir a elas. Pelo que foi discutido nestas páginas podemos pensar que nas entrelinhas da explosão de práticas e políticas conservadoristas talvez seja preciso realizar um exercício de escutar, de fato, que há algo que necessitamos conservar: o cultivo das margens, espessuras porosas possibilitadoras de encontros, conversas, experimentação de outras temporalidades; terreno para construção de 'lares'. O nosso lar só existe em relação ao que nos margeia. Ele não é uma casa fixa em que moramos, é antes a casa entrelaçada constituída no mundo compartilhado. Esse cultivo das margens só se faz, como vimos, pela aproximação. Assim, se a distância e a indiferença nos inclinam ao muro, a proximidade presente nos restitui as margens e a possibilidade de encontro com outrem e o estranhamento.

\section{Referências}

ABBES, C.; HERCKET, A., Micropolítica do processo de acolhimento em saúde. Estudos e Pesquisas em Psicologia, UERJ, RJ, ano 10, $\mathrm{n}^{\circ} .1, \mathrm{p} .151-168,1^{\circ}$ quadrimestre de 2010.

ABREU, G. Conversas entre Educação e Deficiência: por uma política da interdependência nos cotidianos escolares. Dissertação de mestrado, Universidade Federal do Espírito Santo, Programa de Pós-Graduação em Psicologia Institucional, Vitória, Espírito Santo, 2019.

AULETE Dicionário Contemporâneo da Língua Portuguesa. Rio de Janeiro: Lexicon. Disponível do link: http://www.aulete.com.br/conservar, Acesso em: 27 set. 2020.

CANGUILHEM, G. O Normal e o Patológico; tradução Maria Thereza Redig de 
Carvalho Barrocas; revisão técnica de Manoel Barros da Motta; tradução do pósfácio de Pierre Marcherey e da apresentação de Louis Althusser, Luiz Otávio Ferreira Barreto Leite. - 7. ed. - Rio de Janeiro: Forense Universitária, 2011.

CRARY,J. 24/7 - Capitalismo tardio e os fins do sono, tradução: Joaquim Toledo Jr., São Paulo: Cosac Naify, 2014.

DELEUZE, G; GUATTARI, F. Mil platôs-vol. 2. São Paulo: Ed. 34, 1995

DELEUZE, G., Lógica do Sentido; tradução de Luiz Roberto Salinas Fortes. São Paulo: Persperctiva, Ed. Da Universidade de São Paulo, 1974.

DELEUZE,G. Controle e devir. In: DELEUZE, G. Conversações. Rio de Janeiro: Editora 34, 1992.

DERRIDA, J. Anne Dufourmantelle convida Jacques Derrida a falar Da Hospitalidade/ Jacques Derrida [Entrevistado]; Anne Dufourmantelle; tradução de Antônio Romane; revisão técnica de Paulo Ottoni. - São Paulo: Escuta, 2003.

FOUCALULT, M. Vigiar e punir: nascimento da prisão; tradução Raquel Ramalhete, Petrópolis, Vozes, 2014.

FOUCAULT, M. A governamentalidade. In: FOUCAULT, M. Microfísica do poder. São Paulo: Graal, 2006.

FOUCAULT, M. A ordem do discurso. São Paulo: Edições Loyola, 2012.

FOUCAULT, M. O governo de si e dos outros. São Paulo: Ed. Martins Fontes, 2010.

FOUCAULT, M. O que são as luzes? In: FOUCAULT, M. Ditos e Escritos II. Arqueologia das ciências e história dos sistemas de pensamento. Rio de Janeiro: Forense Universitária, 2008.

FOUCAULT, M. Segurança, território e população. São Paulo: Martins Fontes, 1999.

GUATTARI, F. Micropolítica: cartografias do desejo/ Guattari, Suely Rolnick. - 10.ed., Petrópolis, RJ: Vozes, 2010.

GUATTARI, F. Revolução Molecular: pulsações políticas do desejo. São Paulo: Brasiliense, 1977.

GUATTARI, F.; ROLNIK, S. Micropolítica: cartografias do desejo. Rio de Janeiro: Vozes, 1996.

MICHAELIS Dicionário Brasileiro da Língua Portuguesa. São Paulo: Melhoramentos. Disponível no link: https://michaelis.uol.com.br/modernoportugues/busca/portugues-brasileiro/conservar, Acesso em: 27 set. 2020.

PESSOA, F. Lidia, In: Odes de Ricardo Reis in http://www.dominiopublico.gov.br/download/texto/jp000005.pdf , acesso em 27/09/2020.

PORTOCARRERO, V. Reabilitação da concepção de filosofia como ascese no pensamento tardio de Foucault. In: GONDRA, J.; KOHAN, W. (Org). Foucault 80 anos. Belo Horizonte: Autêntica, 2006.

RODRIGUES, H. B.C. Quando Clio encontra Psyche: pistas para um (des)caminho formativo. Cadernos transdisciplinares do Instituto de Psicologia da UERJ. Rio de Janeiro: Ed. UERJ, 1998.

ROLNIK, S., Cidadania e alteridade: o psicólogo, o homem da ética e a reinvenção da 
democracia, In: A cidadania em construção/ Spink, M. J. O. (org); São Paulo: Cortez, 1994.

ROTENBERG, A. Nas margens: alteridade e partilha da experiência. 2015. Dissertação (Mestrado em Psicologia)/Programa de Pós-graduação em Psicologia, Universidade Federal Fluminense, Niterói, 2015.

SOARES, L. B.; MIRANDA, L. L. Produzir subjetividades: o que significa? Estudos e Pesquisas em Psicologia, Vol. 09, nº 02, UERJ. Rio de Janeiro, 2009.

TOUNIER, M. Sexta-feira ou os limbos do pacífico; tradução Fernanda Botelho. $1^{\text {aed. }}$ Rio de Janeiro: BestBolso, 2014.

Adrielly Selvatici Santos
Psicóloga, Mestre em Psicologia Institucional pelo PPGPSI /UFES
E-mail: $\frac{\text { a.selvatici@ yahoo.com.br }}{\text { Janaína Mariano César }}$
Universidade Federal do Espírito Santo (UFES)
E-mail: jhanainacesar@gmail.com
Luciana Vieira Caliman
Universidade Federal do Espírito Santo (UFES)
E-mail: calimanluciana@gmail.com

\footnotetext{
${ }^{1}$ Este artigo inclui desdobramentos da dissertação de mestrado de uma das autoras, a saber: SELVATICI, A. Uma abertura da máquina do mundo: Cogestão e conversa como exercícios de cultivo de margens por entre as rachaduras dos muros. Universidade Federal do Espírito Santo, Programa de Pós-Graduação em Psicologia Institucional, Vitória, Espírito Santo, 2017.
}

${ }^{2}$ Disponível em: https://politica.estadao.com.br/noticias/eleicoes,a-policia-vai-mirar-na-cabecinha-e-fogodiz-novo-governador-do-rio,70002578109. Acesso em 26 Set 2020.

${ }^{3}$ Sentidos encontrados em diferentes dicionários de língua portuguesa. Aqui, utilizou-se os descritos nos dicionários Michaellis e Aulete em suas versões online, disponíveis nas referências bibliográficas.

\footnotetext{
${ }^{4}$ Estrangeiro minoritário é aqui utilizado em remissão ao entendimento do/a estrangeiro (a) como aquele (a) que difere e vivencia com estranhamento o "novo" lugar/circunstância em que chega; ou, mesmo quando não localizado em uma figura, o estrangeiro remete àquilo que é alheio a determinada ordenação, que experimenta e provoca estranhamento ao que está dado. A escolha da expressão "estrangeiro minoritário", em um tom propositadamente hiperbólico, toca a discussão sobre os conceitos de maioria e minoria realizada por Deleuze e Guattari (1995) no segundo platô, quando os autores afirmam que "minoria" e "maioria" não se definem de forma quantitativa, sendo o conceito de maioria relativo a um estado de poder e dominação e o de minoria ao devir, à possibilidade de variação contínua e escape às capturas. Assim sendo, o encontro com os estrangeiros minoritários seria aquele que provoca estranhamento ao que está dado, colocando questão às regulamentações, e, desse modo, possibilitando o disparate para a criação.
} 
${ }^{5}$ Referente à ideia de propriedade privada no contexto capitalístico.

${ }^{6}$ Texto acessado no domínio público. O link de acesso encontra-se nas referências bibliográficas.

${ }^{7}$ Explicitamos que a diferença a qual nos referimos não está centrada em um sujeito ou grupo, não é uma característica ou algo pertencente a alguém. A diferença não está no sujeito ou é um sujeito. "Quando a diferença se torna sujeito, existe ali uma acusação falsa, e sem testemunho, desvio, de anormalidade, do incompleto, castigada de discursos autorizados, renovados, sempre atuais, sempre vigilantes e tensos" (SKLIAR apud ABREU, 2019, p.131). “(...) a diferença não é um sujeito, mas uma relação” (idem, p. 132). É essa compreensão que nos permite pensar a diferença como efeito do encontro e também a dimensão que, por vezes, se tenta barrar na media em que desconcerta, interpela e modifica os sujeitos em jogo.

${ }^{8}$ Mais à frente, a noção do fora será aprofundada na relação com a noção de outrem.

${ }^{9}$ Explicitamos que por Estado não compreendemos as instâncias tradicionalmente compreendidas por uma estrutura estatal governamental. O Estado não tem uma unidade, sendo mais "uma realidade compositória e uma abstração mistificada" (FOUCAULT, 2006: 292), que sobrevive distribuída através de estratégias e táticas de governo, artes de governar atualizadas nas políticas de governos, mas também nos modos como gerimos a casa, a família, o trabalho, etc.

10 Uma das problematizações que compõem este arquipélago problemático é com relação às práticas privatizantes e aos modos de vida privatizados. Ao trazermos Derrida (2003) para esta discussão, o fazemos porque o que o autor está chamando de privado não coincide necessariamente com o privatizado. Com o correr do texto, vamos deslocando este termo para outro. E assim também vamos deslocando um pouco o sentido. Aqui, preferimos deixar as palavras que o autor utiliza porque neste trabalho é importante resguardar um ponto da dimensão da alteridade, por mais que esses termos e sentidos sejam subvertidos mais a frente - como o próprio movimento que se faz pelo encontro com a alteridade: estrangeiramento.

${ }^{11}$ Este dispositivo não é citado pelo autor, uma vez que nem existia no momento em que ministrou o seminário. Decidimos acrescentá-lo porque é muito utilizado por nós hoje em dia.

12 "Em nossa casa" não se refere necessariamente à construção física, mas a uma casa ampliada: o nosso mundo, o nosso espaço, nossa vida, o nosso corpo. Pensar a hospitalidade é pensar a possibilidade de acolhimento e encontro com o que vem de fora e com o fora.

13 24/7 - marca de uma atividade ininterrupta: 24 horas e sete dias por semana.

${ }^{14}$ Nome que Robinson deu a Ilha assim que chegou.

15 Nossa experiência de leitura dos diários era de uma proximidade incrível com Robinson. Era como se estivéssemos frente a frente. Isso nos faz pensar que o diário manifestava a produção de uma escrita para qualquer um (de uma conversa com o impessoal). Ou seria uma conversa com outrem?

${ }^{16}$ A clepsidra ou relógio de água foi um dos primeiros sistemas criados pelo homem para medir o tempo. Trata-se de um dispositivo movido a água, que funciona por gravidade, no mesmo princípio da ampulheta de areia. 
${ }^{17}$ De perda dos calos que permitem que o trabalhador possa segurar e operar a enxada. Tanto o calo como a armadura possuem um aspecto paradoxal. Um calo extremamente grosso afeta a sensibilidade das mãos; afasta por demais o mundo das superfícies nervosas. Em contrapartida, uma mão de pele muito fina não suporta segurar na enxada, rasga-se muito facilmente. Assim também é uma armadura. Se esta não tem suas rachaduras fica muito difícil movimentar-se e até mesmo respirar. É importante que, de algum modo, as coisas transitam. A citação trazida anteriormente traz nela este paradoxo. Este processo fora doloroso para Robinson. Sentiu que havia momentos que não pudera se proteger. Sua pele foi ficando extremamente fina, com pouca regulação das passagens porque não podia mais encontrar outros que pudessem operar outrem. Por isso, essa sensação de hostilidade, invasão.

${ }^{18}$ A palavra semelhante é habitualmente referida àquilo que é da mesma espécie, qualidade, natureza ou forma. Àquilo com que se pode identificar. Mas, aqui neste contexto, tanto no que tange ao texto de Tounier como ao de Deleuze - que estão fundamentando nosso pensamento com relação a este conceito- esta palavra tem um sentido mais relacionado à partilha. A um ser vivo com o qual é possível partilhar experiência.

${ }^{19}$ É importante ressaltar que quando o autor traz outrem como estrutura, ele não o faz pensando como uma estrutura do indivíduo. A estrutura outrem é uma estrutura no mundo. É uma estrutura imanente, que se localiza entre o dentro e o fora. Além disso, no texto, as vezes intercala com o termo sistema.

${ }^{20}$ A imagem que nos chega quando pensamos outrem é a de uma margem espessa, uma extensão de pele, em que os objetos e formas existem de maneira não fechada. Deleuze (1974) traz uma imagem interessante ao falar de um fundo onde os objetos se mordem uns aos outros. Para nós, outrem é esta região, não localizada espacialmente, em que se é possível experimentar um mundo compartilhado. Este é um conceito que ainda nos intriga bastante e esse artigo se concluirá sem que nossas inquietações acerca deste conceito cessem. 